\title{
REFLECTION OF ONOMASTIC PRINCIPLES IN NAMING
}

\author{
${ }^{1}$ Nilufar Sadullaeva, ${ }^{2}$ Maftuna Bakhtiyorova \\ ${ }^{1}$ Associate professor, DSc, National University of Uzbekistan, Tashkent, Uzbekistan. \\ E-mail: nilufar_sadullaeva@mail.ru \\ ${ }^{2}$ Doctoral Student, National University of Uzbekistan, Tashkent, Uzbekistan.
}

\begin{abstract}
:
This article deals with the problems of naming in English and Uzbek languages. The main principles of formation of onomastic units are discussed and the cultural bases of choosing the name are interpreted in the article as well. Theoretical views of well-known linguists are represented from the point of linguocultural aspect. The most important issue in this area was to determine what the Proper Nouns meant. In this paper, we will endeavor to prove the assertion, at the same time accounting for some of the motivations upon which Proper Nouns appear. It may cover the wide range of linguistic and extralinguistic motivations underlying the lexical units - Proper Nouns. Proper Nouns in most cases are not simply a tool of naming, but as linguistic unit they can render an information about the owner. A new exploration of a certain phenomenon, a new perspective for its consideration and contain a new moral and ethical assessment of the phenomenon. Based on this, this article presents linguistic features of Proper Nouns in speech, ethno-linguistic, ethno-cultural, sociolinguistic problems of naming the objects. The analogies and differences between the linguistic phenomenon of Proper Nouns and Common Nouns have been examined in detail.
\end{abstract}

Keywords: interprete, direction, linguistics, culture, phenomenon, unique, direction, universe, experience universe, social, important, historical event.

Article Received: 18 October 2020, Revised: 3 November 2020, Accepted: 24 December 2020

\section{Introduction}

Linguocultural studies can be interpreted today as a new direction in linguistics that is exploring the rapidly evolving, expressing and stabilizing cultures of peoples as a specific form of human relations. According to N.M.Makhmudov: "Linguoculturology studies language as a cultural phenomenon". It is a unique way of comprehencing the world through the prism of a national language, in which language participates as an expression of a particular national mentality. Today, linguoculturology has been formed as a separate linguistic direction in Russian and other foreign linguistics and it is developing as well. This direction, the task of which is to recommend and study the relationship between language and culture, language and ethnos, language and mentality, is just beginning in more comparative research in Uzbek linguistics. " [14: 51].

The linguoculturological direction of linguistics, as noted in a number of studies, relies on the cumulative function of language, through which the life experiences, perceptions of the world, and feelings about knowing the world are reflected in linguistic units and passed down from generation to generation. According to this concept, language is interpreted as the primary form of conceptualizing the universe and generalizing human experiences, preserving knowledge about the universe, socially important historical events in human life.

Well-known sociologist Robert Wuthnow writes in the introductory part of his book Vocabularies of Public Life: "In our century, the analysis of culture is probably more at the center of the human sciences than at any other time." One of the important features of this category of investigations is that they are interdisciplinary in nature. Anthropology, literary criticism, political philosophy, the study of religions, cultural history and cognitive psychology have rich sources and conclusions on this subject, and new ideas can be found in them. " [10:2].

G.Ismailov noted that the study identified three specific features of culture: 1) It has a systemic character: "Culture is a system of programs, norms, standards, paradigms, activities, behaviour and communication of social significance, which are individual, discrete 
coordinates the acts and thus ensures the integrity of social systems and society". 2) Cumulative feature: "Culture is a unique historical memory of the people" [16: 227]. 3) Communicative: "At the communicative level, it means communicating using the linguistic and cultural traditions specific to a community. The result of this level of interaction is reconciliation and mutual understanding between people [8: 4]. Culture is a form of human interaction that manifests itself only in the community in which people interact.

The fact that the various features of the names that exist in the language have attracted the attention of scholars in various fields since ancient times is evidenced by the fact that the ancient Greek scholars Aristotle, Democritus and Heraclitus also commented on the characteristics of Proper Nouns. In his work "Poetics", for example, Aristotle considers the Noun to be one of the parts of speech and describes it as follows: Julius Pollux, who lived in the 1st century BC, created a dictionary of Proper Nouns called Onomastics. The Stoics, including Chrysippus, classified the Proper Nouns as a separate linguistic unit, a group of words.

During the Renaissance and the Middle Ages (T. Gobbs, J. Locke, G. Leibniz) and throughout the nineteenth century (J. Mill, H. Joseph, etc.), the debate over Proper Nouns and their place in the lexical layer of the language continued. The most important issue in this area was to determine what the Proper Nouns meant. During the XVIII-XIX centuries, this problem was studied not only by linguists, but also by philosophers, logicians too.

The great English logician John Stuart Mill (1806-1873) put a lot of effort into studying this problem. According to his interpretation, Proper Nouns do not make sense, they help to know the object as distinctive signs, labels, to distinguish it from other objects. An object, a person's name (nickname) cannot be a complete basis for a description of that object or person. Developing his ideas, J. Mill divides words into two groups:

a) words-signs,

b) descriptive (connotative) words.
Connotative words appeared after the Proper Nouns.

Another English logician, H. Joseph, had expressed conflicting views with J. Mill about Proper Nouns. In his view, Proper Nouns have a broader and more wide meaning than Common Nouns. For example, the phrase "Palikur (man's name, the companion of the legendary Aeneas) was ignored" is more meaningful than the phrase "Man was ignored." [7:16].

In the Middle Ages problems of naming were reflected in the contradictions between the views of realists and nominalists, which emerged in the XI century. The debate revolved around the problems of the existence of a divine being, the possibility of encompassing a common and material being. While nominalism advances the idea that things coexist with concepts, realism argues that general concepts co-exist separately from things, and cites the existence of ideas about divine consciousness as an example.

Materials and Methods

Attempts to unite the views of nominalists and realists under the philosophy of conceptualism were made in the twelfth century by P. Abelard, who argued that general concepts do not exist in isolation or with things, but in the process of studying things by common sense.

In the twentieth century, H. Joseph, in distinguishing between realists, nominalists, and conceptualists, argued that objects with the same individual name had nothing in common except their names; and he promoted the idea that it contradicted the ontological point of view of the realism that followed.

He considered himself in the side of conceptualists, and argued that individuals could not have the same nature because they were individuals, but that general conclusions about innumerable people could be drawn on the basis of certain characteristics (concepts) peculiar to individuals. Analyzing the concept of Proper Nouns of his time, H. Joseph paid special attention to the ideas of the English logician $\mathrm{J}$. Mill, which he considered to be nominalistic. [7: 31-32]. 
In the twentieth century, the logical direction of Proper Nouns was further developed by the well-known English philosopher and logician Bertrand Russell (1872-1970). In his view, the meaning expressed by Proper Nouns in a particular place and time is more precise and scientific than that of common Nouns. Proper Nouns in this respect are very close to demonstrative Pronouns like this or that [9:8].

The Danish linguist Paul Christophersen defines the difference between Proper Nouns and common] Nouns in the fact that the former expresses a definite, concrete meaning, and the latter an abstract meaning. If Proper Nouns are direct names of individuals, while common Nouns are indirect names. Common Nouns first mean the name of a whole group, and then the name is concretized.

The work of the English linguist Alan Gardiner, The Theory of Proper Nouns (1954), took the science of onomastics to a new level. Developing J. Mill's idea that Proper Nouns have no meaning, A. Gardiner argues that Proper Nouns are unique names and represent a set of thematic, concrete ideas about an object, an event. In this respect, Proper Nouns are divided into two groups: a) Proper Nouns that can be embodied and emblem, and b) Proper Nouns that cannot be embodied and emblem. For example, Proper Nouns such as William Shakespeare and the River Thames belong to the group of Proper Nouns that are embodied because they give a general, holistic idea of a particular person (here the great playwright) and the geographical object (here the river). If we simply say William, it means a not generalizing Noun that is incoherent, giving a general idea of a person's name.

Embodied Proper Nouns are Proper Nouns that existed long ago from a historical point of view. For example, anthroponyms such as Amir Temur, Mirzo Ulugbek, Alisher Navoi, Zakhiriddin Mukhammad Babur belong to the group of Proper Nouns, according to this theory, because they embody the symbols of Proper people who played a significant role in the history and culture of our statehood. Anthroponyms such as Temur, Temurbek, Ulugbek, Alisher, Bobur, whose parents dreamed of making their children look like such great persons, are among the most Proper Nouns. [17:12].

Well-known linguist M.I. SteblinKamensky, studying the onomastic lexicon from the point of view of generalization on the basis of the materials of ancient Icelandic literature, notes that the onomastic lexicon used in Icelandic literature did not have the phenomenon of "generalization" at all. In his opinion, any Proper Noun has always expressed a certain denotation, meaning [15: 97].

The doctrine of the "generalization" of Proper Nouns, developed by T. Gobbs at the time, was later further improved by G. Leibniz. According to the German philosopher G. Leibniz, Proper Nouns contain elements of concrete and abstract thinking. This view of the scholar is important from the point of view of considering Proper Nouns in language (in the system of definite elements of communication) and in speech (in the use of these elements from a communicative point of view). As a result of such views, an approach to Proper Nouns in linguistics from an abstract-logical and concrete-historical point of view has emerged [12: 19].

Discussion

The scientific view that there was no element of meaning in the Proper Nouns founded by J.Mill in his time was later developed by such well-known linguists as V.Bryondal, E.Boyssensom, L.Elmslev. As a result, some scholars, including Danish linguist Knud Togebyu, accounted the idea that the Proper Nouns (including rhymes) are synonymous to each other because of having no semantic meaning. Accordingly, a single individual, a person may have several names, and several persons may have a common name, such as names and surnames. There are also opposites to this idea, i.e., Proper Nouns have different characteristics, just like common Nouns, because they are words. Such a view was once based on the Stoic philosophers, and later developed in the nineteenth century by scholars such as H. Joseph, 
J. Mill, and in the twentieth century by $\mathrm{O}$. Espersen. For example, the Danish scientist O. Yespersen noted that "Proper Nouns have more features than common Nouns. Proper Nouns have many connotative characteristics. " [13: 13]

In the $60 \mathrm{~s}$ and $70 \mathrm{~s}$ of the twentieth century, the well-known Russian linguist A.V. Superanskaya was particularly interested in the history of the study of Proper Nouns in linguistics (especially in foreign linguistics), and published a major study entitled "General Theory of Proper Nouns." Along with advancing the idea that names can provide certain information about their object, Professor A.V. Superanskaya notes three types of this information: 1) as a linguistic unit, they serve to name individuals, to distinguish individuals from each other; 2) verbal, in this type of information the attitude of the speaker to the same name is expressed; 3) encyclopedic, encyclopedic information approaches the appellate meaning based on anthroponyms (subtlety in the Uzbek name Nazokat, where the semantics of "noz" dominates) (Superanskaya, 1973).

\section{Results}

Well-known scientist A.A. Reformatsky in his time proposed to distinguish between Proper and common Nouns as follows: Proper Nouns primarily have a nominative function, that is, they serve to name certain objects, events, and common Nouns perform a semantic, i.e. expressive function, that is, they name objects, events, and express the concept of them. (Reformatskiy, 1967)

The assumption that the name of man and things is derived from their inherent nature, especially with emphasis on important features of their nature, is reflected in the scientific work of many philosophers and linguists (Losev 1990; Lotman 1971; Toporov 1989; Florensky 2000).

P. Florensky, who paid special attention to the importance of names in understanding the essence of the object, writes: "The name is such a delicate creature that only through it the spiritual essence is understood." (Florensky 2000: 40).
This approach, which aims to understand the nature of naming and has caused much controversy, is to name people throughout their lives, not at the time of their birth; as well as justifying themselves only when people chose a new name for themselves because of the approval of certain aesthetic preferences or because of their own inner needs. Practice has shown that a new name changes a person, but for this the person himself must be ready for new twists in his life, and the newly chosen name will trigger the beginning of a new era in a person's life. The significance of names is also important in that they embody family and common traditions and customs, which are essentially completely real and unequal in scale and space than individuals (Stepanov 1998: 185).

\section{Conclusion}

This problem is still of interest to linguists, philosophers and other scientists. For example, in 1978, the XIII International Onomastic Congress in Krakow was dedicated to the problem of "Common Nouns and Proper Nouns." The XV International Onomastic Congress held in Leipzig in 1984 discussed the problems of sociolinguistic study of Proper Nouns.

Commenting on the theory put forward by J. Mill and his supporters that Proper Nouns do not express meaning and connotation, E. Grodzinski tries to substantiate the idea that Proper Nouns also have a meaning, an object, an event, a design.

The scientific literature notes that the choice / naming of a newborn baby is not accidental, it is conditioned by family or religious traditions, common onomastic principles in places, stylistic information in names, linguisticexpressive coloring, or simply by tradition, according to various cultural factors possible. (Gilfanova 2008, Gilyazov 2010, Efimenko 2009, Kulikova 2016, Namitokova 2010, shchetinin; Algeo 2000, 1986, Clark 1996, Dunkling 1977, Hanks 2006, Harrison 1990, Lawson 1987, Seeman 1980, Som 1989, Watzlawik 2016). This means that even in the modern culture of many countries, Proper Nouns have retained a certain 
meaning for their owner (Garagul 2012, Mukhin 2007, Kaplan 1999, Miller 2016, Rieger 2015, Rolt 2017, Watzlawik 2016).

In general, there are many pending problems in linguistics in the field of the study of the general problems of Proper Nouns. This will require further research on onomastics in the future.

\section{References}

[1] Abdurakhmonova N., Isroilov J. Personal names spell-checking - a study related to Uzbek Iranian Journal of Social Sciences and Humanities Research. UCT. J. Soc. Human. Resear. (UJSSHR).Takestan, Iran, 2018. Volume 6, Issue 1. P. (№5 Global Impact factor, Impact factor-1,87)

[2] Bram B. Major total conversion in English: the question of directionality. Victoria University of Wellington, 2011. $335 \mathrm{p}$.

[3] Bram B. Major total conversion in English: the question of directionality. Victoria University of Wellington, 2011. $335 \mathrm{p}$.

[4] Charles, Lucille Hoerr. "Drama in Firstnaming Ceremonies". Journal of American Folklore. (1951): 11-35.

[5] Croft W. Syntactic categories and grammatical relation: The cognitive organization. -Chicago: University of Chicago Press, 2003. -133p.

[6] Garwood, S. Gary. "First-name Stereotypes as a Factor in Self-concept and School Achievement. Journal of Educational Psychology. (1976): 482-487.

[7] Hartman, A. Arthur, Robert C. Nicolay, and Jesse Hurley. "Unique Personal Names as a Social Adjustment Factor". Journal of Social Psychology. (1968): 107110.

[8] Joseph H. Language Universals: With Special Reference to Feature Hierarchies. The Hague: Mouton \& Co. 1966.
[9] Lotman Y. A Survey of Semiotics. Dalkey Archive Press: Champaign, London, Dublin.

[10] Russel B. A History of Western Philosophy. - London: Heinemann, 2008. $-499 \mathrm{p}$.

[11] Sadullaeva N.A., Sayfullaeva R.R., Shaxabitdinova Sh. General Philosophical Issues of Language Research.//Journal of critical reviews. Vol 7, Issue 9. (Scopus) 2020. Malaysia. ISSN 2394-5125. -P. 226-231.

http://jcreview.com/index.php?fulltxt=109 $726 \&$ fulltxtj $=197 \&$ fulltxtp $=197-$ 1590302957.pdf

[12] Sadullaeva N.A., Mamatova F.B.Classification of euphemism and its formation in the uzbek language. Journal of critical reviews. Vol 7, Issue 4. March 23, 2020. Malaysia. ISSN 2394-5125. P.426-430 http://www.jcreview.com/fulltext/1971584972123.pdf?1586606700

[13] Wuthnow R. Vocabulary of Public Life. London: Routledge, 2002.-280 p. 